http://jmscr.igmpublication.org/home/ ISSN (e)-2347-176x ISSN (p) 2455-0450

crossref DOI: https://dx.doi.org/10.18535/jmscr/v8i5.41

\title{
Demographic, Prevalence and Clinical Profile of Severe Malnourished Infants Admitted to the Malnutrition Treatment Centre of Bikaner Hospital, Rajasthan
}

\author{
Authors \\ Seema Singh ${ }^{*}$, Rita Mishra ${ }^{2}$ \\ ${ }^{1,2} \mathrm{Ph} . \mathrm{D}$, Department of food and Nutrition, Swami Keshwanand Rajasthan Agricultural University, \\ Bikaner, Rajasthan (India) \\ *Corresponding Author \\ Dr Seema Singh
}

Ph.D, Department of food and Nutrition, Swami Keshwanand Rajasthan Agricultural University, Bikaner, Rajasthan (India)

\begin{abstract}
Malnutrition continuous to be a major public health problem in developing countries. It is the most important risk factor for the burden of diseases. The present study was undertaken to study the demographic details and clinical profile of the patients admitted to the malnutrition treatment centre of a P.B.M government hospital of Bikaner, Rajasthan. This was a cross-sectional study done in the malnutrition treatment centre of Bikaner hospital, Rajasthan state over a period of four months. It was carried out on 84 infants in the age group of 06 to 24 months with severe acute malnourished, diagnosed on the basis of WHO classification. Out of 84 subjects, more than half of the infants $(53.57 \%)$ were belonged to the 6-12 months of age group. Majority of the infants (88.10\%) were Hindus and maximum subjects were belonged to schedule caste. About 46.43 per cent of subjects were born with low birth weight. All the subjects were belonged to the low income group. Most of the mothers (82.14\%) and fathers $(55.52 \%)$ were illiterate. More than half of the subjects $(59.52 \%)$ were not completely immunized. Maximum subjects were found to be severe underweight (78.5\%), stunted (45.24\%) and wasted (79.76\%). majority of the subjects had occasional occurrence of cold \& cough (50.00\%), fever (51.19\%) and diarrhoea (44.05\%) respectively. Vomiting was noted to be rarely occurring (38.10\%) in the majority of the subjects. The common co-morbidity found was dehydration (26.19\%) and bronchopneumonia $(21.43 \%)$ followed by pyrexia with anemia (17.86\%), severe anemia (13.10\%), SAM without medical complications (7.14\%), measles (5.95\%), tuberculosis (2.38\%), dysentery (2.38\%), cardiac disease $(1.19 \%)$, lesion with multiple ulcer $(1.19 \%)$ and HIV+ (1.19\%). Timely identification and treatment of various co-morbidities is likely to break undernutrition cycle and to decrease mortality and improve outcome.
\end{abstract}

Keywords: Clinical Profile, Malnutrition, Malnutrition Treatment Centre, Co-morbidity. 


\section{Introduction}

Childhood undernutrition remains a key public health challenge in India and is a significant contributor of under-five mortality as these children have significantly higher risk of mortality and morbidity ${ }^{1}$. The strongest and most consistent relation between malnutrition and an increased risk of death has been observed for diarrhoea and acute respiratory infection, although evidence also suggests a potentially increased risk of death from malaria and measles ${ }^{2}$. Data from developing countries indicate that 56 per cent of child deaths are attributable to the malnutrition's potentiating effects and 83 per cent of these were attributable to mild-to-moderate malnutrition ${ }^{3}$. In India, National Family Health Survey-4 shows that about 35.7 per cent of the children in India under 5 years of age are underweight, 38.4 per cent are stunted, and approximately 21 per cent are moderately to severely wasted ${ }^{4}$. Malnutrition not only increases the likelihood of acute and chronic diseases but also reduces long-term physical development, cognitive skills and consequently, has a negative effect on school enrollment and productivity in later life ${ }^{5}$.

Severe acute malnutrition is defined by a very low weight for height (below $-3 \mathrm{z}$ scores of the median WHO growth standards), by visible severe wasting or by the presence of nutritional oedema $^{6,7}$. Severe acute malnutrition puts the children at a greater risk of dying from common infections, increases the frequency and severity of such infections and contributes to delayed recovery. In addition, the interaction between severe acute malnutrition and infections can create a potentially lethal cycle of worsening illness and deteriorating nutritional status. Poor nutrition in first thousand days of a child's life leads to stunted growth which is irreversible and is associated with impaired cognitive ability and school performance. There is scarcity of data on co-morbidities associated with severe acute malnutrition. With this background a study was conducted on demographic and the clinical profile in severely malnourished children admitted to malnutrition treatment centre ${ }^{8}$.

\section{Materials and Methods}

This was a cross-sectional study conducted in the malnutrition treatment centre (MTC) of the P.B.M government hospital at Bikaner district of Rajasthan state over a period of four months. A written permission was obtained from the department of pediatrics of P.B.M government hospital before starting the study. All the infants of the age group 06 to 24 months either male or female who were admitted during the study period in the MTC with the diagnosis of severe acute malnutrition (SAM) based on WHO classification were included in the study and whose parents did not consent to be part of the study were excluded from the study.

After obtaining informed consent from parents, details of the child such as gender, age, religion, caste, birth weight of the child, educational level of their parents, income status of their families were collected. Information regarding the immunization and morbidity status of the infants were also collected. The information was recorded through interviewing of mother or person feeding the child. Questions were probed to the individual mother in a comfortable environment and the responses were recorded. The detailed physical examination and anthropometry measurements were recorded and analysed by using WHO 2006 Growth Standard. Three commonly used under nutrition indicators namely stunting, underweight and wasting were used to evaluate the growth status of the subjects.

\section{Statistical Analysis}

Data was entered in M.S office XL sheet and expressed as frequencies and percentages. Anthropometric analysis was done by using WHO Anthro software (version 3.2.2). This software was calculating nutritional indicator as per recent WHO growth standard using $\mathrm{Z}$ score. 


\section{Result}

A total of 84 severe acute malnourished infants belonging to the age group of 06 to 24 months who were admitted in the malnutrition treatment centre were enrolled in the study. Out of which, 51.19 per cent were male and 48.81 per cent were female. More than half of the infants $(53.57 \%)$ were belonged to the 6-12 months of age group, 38.10 percent belonged to the 13 to 18 months of age group and only 8.33 percent were belonged to the 19-24 months of age group. Majority of the infants i.e., 88.10 per cent were Hindus and 11.90 were Muslim. As regard to caste of all the subjects, it was found that 78.57 per cent belonged to schedule caste followed by 17.86 per cent of other backward class and only 3.57 per cent of subject's belonged to general caste respectively. About 46.43 per cent of subjects were having less than $2.5 \mathrm{~kg}$ which is considered low birth weight of infants, 33.33 per cent were having birth weight from 2.5 to $3.0 \mathrm{~kg}, 4.76$ per cent were having birth weight of $>3 \mathrm{~kg}$ and 15.48 per cent don't have a birth weight record due to home delivery or was not able to recall the birth weight of their child. The families of all the infants under the study belonged to the low-income group. None of the subjects belonged to the high or medium-income group. Most of the mothers i.e. 82.14 per cent were illiterate and 55.95 per cent fathers were illiterate (Table 1).

Table 1: Demographic details of the subjects

\begin{tabular}{|c|c|c|c|}
\hline S.No. & Characteristics & Frequency & Percentage \\
\hline & & \multicolumn{2}{|c|}{ Total subjects $(\mathrm{N}=84)$} \\
\hline \multirow[t]{3}{*}{1.} & Gender & & \\
\hline & Male & 43 & 51.19 \\
\hline & Female & 41 & 48.81 \\
\hline \multirow[t]{4}{*}{2.} & Age of the infants (in months) & & \\
\hline & $6-12$ & 45 & 53.57 \\
\hline & $13-18$ & 32 & 38.10 \\
\hline & $19-24$ & 7 & 8.33 \\
\hline \multirow[t]{3}{*}{3.} & Religion & & \\
\hline & Hindu & 74 & 88.10 \\
\hline & Muslim & 10 & 11.90 \\
\hline \multirow[t]{4}{*}{4.} & Caste & & \\
\hline & General & 3 & 3.57 \\
\hline & Other backward class & 15 & 17.86 \\
\hline & Scheduled caste & 66 & 78.57 \\
\hline \multirow[t]{5}{*}{5.} & Birth weight of the child (in Kg) & & \\
\hline & $<2.5$ & 39 & 46.43 \\
\hline & $2.5-3.0$ & 28 & 33.33 \\
\hline & $>3.0$ & 4 & 4.76 \\
\hline & Don't know & 13 & 15.48 \\
\hline \multirow[t]{4}{*}{6.} & Annual income(Rs) (Lacs/year) & & \\
\hline & Low (below 2.5) & 84 & 100 \\
\hline & Medium (2.5-6) & 0 & 0 \\
\hline & High (6 \& above) & 0 & 0 \\
\hline \multirow[t]{6}{*}{7.} & Educational level of the mother & & \\
\hline & Illiterate & 69 & 82.14 \\
\hline & Primary level & 11 & 13.10 \\
\hline & Secondary level & 3 & 3.57 \\
\hline & Higher secondary & 1 & 1.19 \\
\hline & Intermediate and above & 0 & 0 \\
\hline \multirow[t]{6}{*}{8.} & Educational level of the father & & \\
\hline & Illiterate & 47 & 55.95 \\
\hline & Primary level & 22 & 26.19 \\
\hline & Secondary level & 12 & 14.26 \\
\hline & Higher secondary & 2 & 2.38 \\
\hline & Intermediate and above & 1 & 1.19 \\
\hline
\end{tabular}


Immunization coverage of the subjects showed that more than $(59.52 \%)$ half of the subjects were not completely immunized, 27.38 per cent were complete up to the age and 13.10 per cent were not immunized (Table 2).

Table 2: Immunization status of the subjects

\begin{tabular}{|l|c|c|}
\hline Immunization status & Frequency & Percentage \\
\hline Complete & 23 & 27.38 \\
\hline Incomplete & 50 & 59.52 \\
\hline Unimmunized & 11 & 13.10 \\
\hline
\end{tabular}

Table (3) shows that 78.57 per cent of infants were admitted in MTC with severe underweight, 15.48 per cent with moderately underweight and only 5.95 per cent of infants admitted were in the mild category. It is quite clear from table that none of the subjects was in a normal category using weight for age as an indicator.

Categorization of subjects based on height for age showed that most of the subjects were found to be severely $(45.24 \%)$ stunted followed by moderately stunted $(23.81 \%)$ and mild stunted (14.48\%) with 16.67 per cent grouped as normal. According to weight for height, 79.76 per cent were found to be severe wasted, 16.67 per cent moderately, 2.38 per cent were mildly and only 1.19 per cent subjects were found as normal.

Table 3: Distribution of subjects of age group 06 to 24 months according to the underweight, stunted and wasted

\begin{tabular}{|l|c|c|c|c|c|}
\hline Characteristics & $\begin{array}{c}\text { Severe } \\
\text { malnourished } \\
(<-3.00 S D)\end{array}$ & $\begin{array}{c}\text { Moderate } \\
\text { malnourished } \\
(\mathbf{- 3 . 0 0} \text { to } \mathbf{- 2 . 0 1} \text { SD) }\end{array}$ & $\begin{array}{c}\text { Mild malnourished } \\
\mathbf{( 2 . 0 0} \text { to 1.01 SD) }\end{array}$ & $\begin{array}{c}\text { Normal } \\
( \pm \mathbf{1 . 0 0} \text { SD) }\end{array}$ & $\begin{array}{c}\text { Total } \\
\mathbf{( N = 8 4 )}\end{array}$ \\
\hline Underweight & $66(78.57)$ & $13(15.48)$ & $5(5.95)$ & $0(0.00)$ & $84(100)$ \\
\hline Stunted & $38(45.24)$ & $20(23.81)$ & $12(14.28)$ & $14(16.67)$ & $84(100)$ \\
\hline Wasted & $67(79.76)$ & $14(16.67)$ & $2(2.38)$ & $1(1.19)$ & $84(100)$ \\
\hline
\end{tabular}

Number in parenthesis indicates the percentage of the children

Table (4) shows the prevalence of certain common health problems like cold \& cough, diarrhoea \& constipation, fever, vomiting and the other comorbidities associated with severe acute malnutrition. Table clearly shows that majority of the subjects had occasional occurrence of cold \& cough $(50.00 \%)$, fever $(51.19 \%)$ and diarrhoea $(44.05 \%)$ respectively. Vomiting was noted to be rarely occurring $(38.10 \%)$ in the majority of the subjects. Whereas, percentage of the frequent occurrence of cold and cough, fever, vomiting and diarrhoea were found to be 42.86 per cent, 36.90 per cent, 14.29 per cent and 34.52 per cent respectively. Occurrence of other co-morbidity status associated with malnutrition were dehydration (26.19\%), bronchopneumonia $(21.43 \%)$, pyrexia with anemia $(17.86 \%)$, severe anemia (13.10\%), SAM without medical complications (7.14\%), measles (5.95\%), tuberculosis $(2.38 \%)$, dysentery $(2.38 \%)$, cardiac disease $(1.19 \%)$, lesion with multiple ulcer $(1.19 \%)$ and HIV+ $(1.19 \%)$ reported in subjects who are admitted in MTC (malnutrition treatment center) with severe acute malnutrition. 
Table 4: Morbidity Status of the subjects

\begin{tabular}{|c|c|c|c|}
\hline S.No. & Characteristics & Frequency & Percentage \\
\hline \multirow[t]{4}{*}{1.} & Cold and cough & & \\
\hline & Frequently & 36 & 42.86 \\
\hline & Occasionally & 42 & 50.00 \\
\hline & Rarely & 6 & 7.14 \\
\hline \multirow[t]{4}{*}{2.} & Fever & & \\
\hline & Frequently & 31 & 36.90 \\
\hline & Occasionally & 43 & 51.19 \\
\hline & Rarely & 10 & 11.90 \\
\hline \multirow[t]{5}{*}{3.} & Vomiting & & \\
\hline & Frequently & 12 & 14.29 \\
\hline & Occasionally & 26 & 30.95 \\
\hline & Rarely & 32 & 38.10 \\
\hline & Never & 14 & 16.67 \\
\hline \multirow[t]{5}{*}{4.} & Diarrhoea/constipation & & \\
\hline & Frequently & 29 & 34.52 \\
\hline & Occasionally & 37 & 44.05 \\
\hline & Rarely & 16 & 19.05 \\
\hline & Never & 2 & 2.38 \\
\hline \multirow[t]{12}{*}{5.} & Other & & \\
\hline & Dehydration & 22 & 26.19 \\
\hline & Bronchopneumonia & 18 & 21.43 \\
\hline & Pyrexia with anemia & 15 & 17.86 \\
\hline & Severe anemia & 11 & 13.10 \\
\hline & SAM without medical complications & 6 & 7.14 \\
\hline & Measles & 5 & 5.95 \\
\hline & Tuberculosis & 2 & 2.38 \\
\hline & Dysentery & 2 & 2.38 \\
\hline & Cardiac disease & 1 & 1.19 \\
\hline & Lesion with multiple ulcer & 1 & 1.19 \\
\hline & HIV & 1 & 1.19 \\
\hline
\end{tabular}

\section{Discussion}

In our study, severe acute malnutrition was more common in among 06 to 12 months of age group, which was similar to other studies ${ }^{9}$. Almost equal numbers of male and females were admitted, indicating that there is not much sex bias. Similarly almost equal numbers of male and female SAM children were reported in many studies $^{10,11,12}$. In our study, majority of the subjects $(87.88 \%)$ were from the Hindu community, and only 12.12 per cent were from the Muslim religion. None of the subjects belonged to other religion of society. This is due to the location of the hospital, where the majority of the households belong to the Hindu community. This shows that, percent of different community may differ locality and majority of household wise. According to the Rajasthan religion census, the majority $(88.49 \%)$ of the state population is constituted by Hindus ${ }^{13}$. Choudhary et al. also found the majority of the cases i.e., 88 per cent were Hindus ${ }^{14}$.A baby's weight at birth is a strong indicator of maternal and newborn health and nutrition. In a present study, birth weight of maximum subjects were having less than $2.5 \mathrm{~kg}$ which is considered low birth weight of infants. Same was recorded by Sethi et al. in Rajasthan ${ }^{15}$. All the subjects under the study belonged to the low-income group. Yadav and Dunkwal also found in their study that all the subjects belonged to the low-income group ${ }^{16}$. Most of the mothers of the subjects admitted were illiterate and more than half of the fathers were also found to be illiterate during the present study. Education of parents is very important in upbringing a healthy child, especially maternal education, is a powerful predicator of children's nutritional status. Mother's education plays a vital role in increased receptivity to knowledge and awareness related to nutritional requirements of their infants ${ }^{17}$. 
Mahmood et al. also found in their study that most of the mothers were illiterate $(69.9 \%)^{18}$.

Immunization is one of the most practical and economical ways of preventing disease. Immunizing agents are specific for a particular disease and stimulate the defense mechanism of the body against that particular disease only. The Government of India launches various immunization programs from time to time to propagate immunization on a mass scale. For wholesome health completion of immunization schedule is necessary for each child. In this study more than $(59.52 \%)$ half of the subjects were not completely immunized, 27.38 per cent were complete up to the age and 13.10 per cent were not immunized. The major cause for not immunizing the child was fear of side effects followed by unawareness of need for immunization. The common reasons for partially immunizing the child were a postponement of immunization, due to visit to the native place, illness of the child or another sibling not well, time of immunization inconvenient, lack of information about venue and place, schedule and prescribed age of immunization. Lack of appropriate information is still the main hurdle for the success of primary immunization in rural $\operatorname{areas}^{19}$.

Severe malnutrition is not only an important cause of morbidity and mortality, but also leads to impairment of physical and possibly mental growth of those who survive. In addition to critical care, a nutritional therapy followed by nutritional rehabilitation is a very important aspect for these children. In a present study, a high prevalence of severely underweight, stunted and wasted among infants in the age group of 06-24 months were found. This high prevalence was due to lack of awareness about malnutrition in community especially in rural population due to high illiteracy level of mothers and lower socioeconomic status of the family and in India parents generally do not seek medical advice for these malnourished children until they suffer from some of the acute complications of severe acute malnutrition

e.g.

diarrhoea,

vomiting, bronchopneumonia, fever, skin infection etc. High prevalence of underweight among children 0-5 years in western Rajasthan also reported by Singh et $\mathrm{al}^{20}$. Acharya and Meena, who also found $(37.06 \%)$ prevalence of underweight in a rural community, Bikaner but during the present study greater percentage of the subjects were found to be underweight ${ }^{21}$. Choudhary et. al. also found a high prevalence of severely stunted on patients of severe acute malnutrition admitted in malnutrition treatment corner in Jodhpur ${ }^{22}$. A study conducted by Parameshwari et. al. also reported a higher percentage of wasting among children. They reported that according to WHO recommended classification the prevalence of wasting (weight for height <Median -2SD) was 44 per cent while that of severe wasting (weight for height $<$ Median -3SD) was 20 per cent ${ }^{23}$. Aprameya et al. also reported in their study that 65.93 per cent of children had weight for height/length $\mathrm{z}$ score (WHZ) below $-3 \mathrm{SD}^{24}$.

Severe acute malnutrition puts the children at a greater risk of dying from common infections, increases the frequency and severity of such infections and contributes to delayed recovery. In a present study the most common health problems like cold \& cough, diarrhoea \& constipation, fever, vomiting and the other co-morbidities associated with severe acute malnutrition. Results shows that majority of the subjects had occasional occurrence of cold \& cough $(50.00 \%)$, fever $(51.19 \%)$ and diarrhoea $(44.05 \%)$ respectively. Vomiting was noted to be rarely occurring $(38.10 \%)$ in the majority of the subjects. In this study, the common co-morbidity found was dehydration (26.19\%) and bronchopneumonia $(21.43 \%)$ followed by pyrexia with anemia $(17.86 \%)$, severe anemia $(13.10 \%)$, SAM without medical complications (7.14\%), measles $(5.95 \%)$, tuberculosis $(2.38 \%)$, dysentery $(2.38 \%)$, cardiac disease $(1.19 \%)$, lesion with multiple ulcer $(1.19 \%)$ and HIV+ $(1.19 \%)$ reported in subjects who are admitted in MTC (malnutrition treatment center) with severe acute malnutrition. Similarly, 
Chaudhary et al. in their hospital-based study also reported that most common co-morbidity associated with severe malnutrition was gastrointestinal $(60 \%)$ followed by respiratory tract infection (52\%), UTI (4\%) and otitis media (2.7\%). Other associated co-infection was tuberculosis $(9.3 \%)$, dysentery $(6.7 \%)$, measles (4\%), HIV (4\%) and Malaria (1.3\%). They also found that the most common presenting symptoms were fever, vomiting, loose motion and cough ${ }^{22}$.

\section{Conclusion}

Timely identification and management of the comorbid conditions is very important to break the malnutrition-disease-cycle, to decrease the mortality and to improve outcome in severely malnourished children.

\section{References}

1. Dhirar N, Dudeja, S, Khandekar, J and Bachani, D. Childhood morbidity and mortality in India-analysis of national family health survey 4 (NFHS-4) findings. Indian Pediatr 2018; 55:335-338.

2. Rice AL, Sacco L., Hyder A, Black RE. Malnutrition as an underlying cause of childhood deaths associated with infectious diseases in developing countries. Bull World Health Organ 2000; 78:1207-1221.

3. Pelletier DL, Frongillo EA, Schroeder DG and Habicth JP. The effects of malnutrition on child mortality in developing countries. Bull World Health Organ 1995; 73:443448.

4. National Family Health Survey. India. Mumbai: International Institute for Population Sciences 2017.

5. Kar BR, Rao SL, Chandramouli BA. Cognitive development in children with chronic protein energy malnutrition. Behav Brain Funct 2008; 4:31.

6. World Health Organization and UNICEF. Global Strategy for Infant and Young Child Feeding, WHO, Geneva 2007.
7. World Health Organization. Management of Severe Malnutrition: A manual for physicians and other senior health workers, WHO, Geneva 1999.

8. Arya AK, Lal P and Kumar P. Comorbidities in children with severe acute malnutrition-a tertiary care centre experience. International Journal of Contemporary Medical Research 2017; 4(5):1086-1088.

9. Jain S, Borle, Agrawal SS, Mishra MK and Gupta SK. Assessment of Infant and Young Child Feeding Practices among mothers in rural Madhya Pradesh. Indian J of Comm Med 2014; 5(4):419-423.

10. Mamidi RS, Kulkarni, B, Radhakrishna, $\mathrm{KV}$ and Shatrugna V. Hospital Based Nutrition Rehabilitation of Severely Undernourished Children Using Energy Dense Local Foods. Indian Pediatrics 2010; 47(8):687-693.

11. Taneja G, Dixit S, Khatri AK, Yesikar V, Raghunath D and Chourasiya S. A study to evaluate the effect of nutritional intervention measures on admitted children in selected nutrition rehabilitation centers of Indore and Ujjain divisions of the state of Madhya Pradesh (India). Indian J Community Medicine 2012; 37(2):107-115.

12. Thakur GS, Singh, HP and Patel C. Locally-Prepared Ready-to-Use Therapeutic Food for Children with Severe Acute Malnutrition: A Controlled Trial. Indian Pediatr 2013; 50:295-299.
13. Census
(2011).
Rajasthan, https/www.census2011.co/data/religion/sta te/8-Rajasthan.html.

14. Choudhary M, Sharma D, Nagar RP, Gupt BD, Nagar $\mathrm{T}$ and Pandita A. Clinical Profile of Severe Acute Malnutrition in Western Rajasthan: A Prospective Observational Study from India. J of Pedia Neo Care 2015; 2(1):57. 
15. Sethi AI, Gandhi D, Varia JJ, Bhageria V, Darshan V. The burden of Low Birth Weight and Malnutrition among Newborn Babies in Rajasthan, India. National $\mathbf{J}$ of Med Resear 2016; 6(3):265-267.

16. Yadav A and Dunkwal V. Efficacy of Health Food Developed For Malnourished Preschoolers Attending Anganwadi Center. M.Sc Thesis, SKRAU, Bikaner (Rajasthan) 2014.

17. Yimer G. Malnutrition among children in Southern Ethiopia: Levels and risk factors. Ethiop. J. Health Dev 2000; 14(3):283292.

18. Mahmood SE, Srivastava A, Shrotriya VP and Mishra P. Infant feeding practices in the rural population of north India. $\mathrm{J}$ of Family and Comm Med 2012; 19(2):130135.

19. Kar M, Reddaiah VP and Kant K. (2001). Primary immunization status of children in slum areas of South Delhi-The challenge of reaching the urban poor. Indian $\mathrm{J}$ of Com Med 2001; 26(3):151-154.

20. Singh MB, Fotedar R, Narayan JL. and Anand PK. Studies on the nutritional status of children aged 0-5 years in a drought-affected the desert area of western Rajasthan, India. Public Health Nutri 2007; 9(8):961-967.

21. Acharya R and Meena RA. A descriptive cross-sectional study to assess the prevalence of malnutrition in children under five years age in rural community Bikaner, Rajasthan. Int $\mathbf{J}$ of Commu Med Pub Health 2016; 3(1):299-302.

22. Choudhary M, Sharma, D, Nagar RP, Gupta BD, Nagar T. and Pandita A. Clinical Profile of Severe Acute Malnutrition in Western Rajasthan: A Prospective Observational Study from India. J of Pedia Neo Care 2015; 2(1):57.
23. Parameshwari P, Banumathi PG, Jaiganesh D, Dharani RS and Ravishanker P. A study on malnutrition among children attending Anganwadi centres by IAP and WHO classification. Int $\mathbf{J}$ of Recent Trends in Sci and Tech 2016; 19(3): 414-417.

24. Apremeya HS, Kamath SP, Kini PK, Baliga BS, Shenoy UV and Jain A. Socioepidemiological determinants of Severe Acute Malnutrition and effectiveness of nutritional rehabilitation centre in its management. Inte $\mathbf{J}$ of Health Allied Sci 2015; 4(1):148-153. 